\title{
Effect of Postweld Heat Treatment on Microstructure, Hardness, and Tensile Properties of Laser-Welded Ti-6Al-4V
}

\author{
ABU SYED H. KABIR, XINJIN CAO, JAVAD GHOLIPOUR, PRITI WANJARA, \\ JONATHAN CUDDY, ANAND BIRUR, and MAMOUN MEDRAJ
}

\begin{abstract}
The effects of postweld heat treatment (PWHT) on 3.2-mm- and 5.1-mm-thick Ti-6Al-4V butt joints welded using a continuous wave $(\mathrm{CW}) 4-\mathrm{kW}$ Nd:YAG laser welding machine were investigated in terms of microstructural transformations, welding defects, and hardness, as well as global and local tensile properties. Two postweld heat treatments, i.e., stress-relief annealing (SRA) and solution heat treatment followed by aging (STA), were performed and the weld qualities were compared with the as-welded condition. A digital image correlation technique was used to determine the global tensile behavior for the transverse welding samples. The local tensile properties including yield strength and maximum strain were determined, for the first time, for the laser-welded Ti-6Al-4V. The mechanical properties, including hardness and the global and local tensile properties, were correlated to the microstructure and defects in the as-welded, SRA, and STA conditions.
\end{abstract}

DOI: $10.1007 / \mathrm{s} 11661-012-1230-5$

(C) The Minerals, Metals \& Materials Society and ASM International 2012

\section{INTRODUCTION}

FOR structural applications, the utilization of titanium alloys has several benefits over steel and aluminum alloys. Specifically, the combination of low density, good tensile properties (up to a temperature of $873 \mathrm{~K}$ $\left[\begin{array}{ll}600 & \\ & \end{array}\right]$ ), good corrosion resistance, and chemical compatibility with, for example, carbon fiber-reinforced composite renders a high attraction for applications especially in aerospace. ${ }^{[1,2]}$ Of the various titanium grades, the most popular is Ti-6Al-4V, an $\alpha+\beta$ alloy that contains 6 wt pet Al to stabilize the HCP $\alpha$-phase and 4 wt pct $\mathrm{V}$ to stabilize the body-centered cubic $\beta$-phase at room temperature.

Of importance for increasing the application of titanium alloys is the development of cost-effective joining processes that render high mechanical performance of the structural assembly. For fusion welding processes, titanium exhibits some excellent characteristics such as good fluidity of the molten metal and low thermal conductivity. ${ }^{[3]}$ However, the high reactivity of titanium with atmospheric gases at temperatures above $673 \mathrm{~K}$ $\left(400{ }^{\circ} \mathrm{C}\right)$ and especially in the liquid state ${ }^{[4]}$ has traditionally led to the utilization of high-vacuum electron beam

ABU SYED H. KABIR, formerly Master Graduate Student, Concordia University, Montréal, Québec H3G 1M8, Canada, is now Ph.D. Candidate, McGill University, Montréal, Québec H3A 0C5, Canada. XINJIN CAO, JAVAD GHOLIPOUR, and PRITI WANJARA, Research Officers, are with the Aerospace Manufacturing Technology Center, Institute of Aerospace Research, National Research Council Canada, Montréal, Québec H3T 2B2, Canada. Contact e-mail: Xinjin.Cao@cnrc-nrc.gc.ca JONATHAN CUDDY and ANAND BIRUR, Senior Engineers, are with the StandardAero Limited, Winnipeg, Manitoba R3H 1A1, Canada. MAMOUN MEDRAJ, Professor, is with the Department of Mechanical and Industrial Engineering, Concordia University.

Manuscript submitted October 20, 2011.

Article published online June 3, 2012 welding for component assembly, particularly for the aerospace industry. Recent advancements in high-power laser technology have resulted in the ability to use lasers for the manufacturing, repair, and overhaul of titanium alloys for aircraft structures and aero engine components. With adequate shielding gas protection, titanium alloys can be laser welded and the joints can be similar in quality and performance to the electron beam welds. Particularly, the high energy density of laser welding allows low heat input and fast welding speeds (high productivity) that can produce a high aspect ratio weld (penetration depth/bead width) with a narrow heat-affected zone (HAZ), low distortion, and high weld quality including refined prior- $\beta$ grain size. In addition, laser welding of titanium alloys with local shielding gas protection offers manufacturing flexibility as well as ease of automation. ${ }^{[5-7]}$ Of the various titanium grades, Ti-6Al-4V has been reported to have good weldability, but its strength, ductility, and toughness may be significantly varied, depending on the thermal cycling history during manufacturing. ${ }^{[8]}$ Despite the extensive amount of literature on the weldability of Ti-6Al-4V, the effect of postweld heat treatment (PWHT) on the mechanical performance of Ti-6Al-4V laser welds has not been well understood. The aim of this work is, therefore, to discuss the effects of two common PWHT processes typically utilized for Ti-6Al-4V welds, namely stress-relief annealing (SRA) and solution heat treatment followed by aging (STA), on the weld properties and to compare these with the as-welded performance.

\section{EXPERIMENTAL PROCEDURE}

\section{A. Material, Welding Equipment, and Procedure}

As-received mill-annealed grade $5 \mathrm{Ti}-6 \mathrm{Al}-4 \mathrm{~V}$ sheets (AMS 4911) with two thicknesses (3.2 $\mathrm{mm}$ and $5.1 \mathrm{~mm}$ ) 
were sectioned into coupons with dimensions of roughly $75 \mathrm{~mm}$ in length by $38 \mathrm{~mm}$ in width. Table I shows the presence of alloying elements in the Ti-6Al-4V material.

The faying and adjacent surfaces of each specimen were brushed and then cleaned with ethanol to remove any surface oxides and contaminants prior to clamping and welding. The welding equipment consisted of a 4-kW continuous wave solid-state $\mathrm{Nd}$ :YAG laser system equipped with an $\mathrm{ABB}$ robot and a magnetic holding fixture. A collimation lens of $200 \mathrm{~mm}$, a focal lens of $150 \mathrm{~mm}$, and a fiber diameter of $0.6 \mathrm{~mm}$ were used to produce a focusing spot diameter of approximately $0.45 \mathrm{~mm}$. Because of the high reactivity of titanium with atmospheric elements, especially at high temperatures and in the liquid state, adequate measures were taken to shield the molten pool and the heated surfaces until these regions were cooled below $573 \mathrm{~K}\left(300^{\circ} \mathrm{C}\right)$. Highpurity argon at a flow rate of $23.6 \mathrm{~L} \mathrm{~min}^{-1}(50 \mathrm{cfh})$ was used to shield the top surface of the work piece. The shielding of the root and the trailing gas shield on the top surface were performed using helium at a total flow rate of $66.1 \mathrm{~L} \mathrm{~min}^{-1}(140 \mathrm{cfh})$. The laser beam was focused at $1 \mathrm{~mm}$ below the top surface of the work piece; i.e., the defocusing distance was fixed at $-1 \mathrm{~mm}$ in this study. The joint gap was fixed at $0.3 \mathrm{~mm}$ for both thicknesses and Ti-6Al-4V filler wire (AMS 4956A ELI), with a nominal diameter of $1.14 \mathrm{~mm}$, was fed at a fixed angle of $30 \mathrm{deg}$ relative to the top surface of the work piece. The filler wire feed rate was calculated from the volume flow rate constancy equation

$$
\text { Wire feed rate }=\frac{\text { Welding speed } \times \text { Gap area }}{\text { Filler wire area }}
$$

Table II lists the main laser processing parameters used in this work. These optimum parameters were selected based on the previous work. ${ }^{[9-13]}$

\section{B. Postweld Heat Treatments}

In this study, two PWHT conditions were investigated: SRA (an annealing heat treatment to relieve

Table I. Composition of the Ti-6Al-4V Material Used in this Study

\begin{tabular}{lcccccc}
\hline Element & Mn & Mo & Fe & V & Al & Ti \\
\hline Wt pct & $<0.01$ & $<0.01$ & 0.17 & 4.02 & 6.35 & Balance \\
\hline
\end{tabular}

stress) and STA (a full heat treatment to solution heat treat and age). The SRA was performed by heating the specimen to $811 \mathrm{~K}\left(538{ }^{\circ} \mathrm{C}\right)$ for 4 hours followed by argon quenching, whereas the STA was carried out by solution heat treating the specimen at $1186 \mathrm{~K}\left(913{ }^{\circ} \mathrm{C}\right)$ for 45 minutes followed by argon quenching and then aging at $811 \mathrm{~K}\left(538{ }^{\circ} \mathrm{C}\right)$ for 4 hours followed by argon quenching. As the temperatures and cycling for the SRA and aging heat treatments are similar, the effect of the postweld aging was also investigated in this way.

\section{Microscopy}

Three transverse sections were cut from each joint for metallographic examination to analyze the weld integrity and microstructure using optical microscopy. After sectioning, the samples were mounted using cold-setting epoxy resin, ground, and then polished using automated techniques to produce a mirror-like finish. Kroll's reagent (1 to $3 \mathrm{~mL} \mathrm{HF}+2$ to $6 \mathrm{~mL} \mathrm{HNO}_{3}+$ $100 \mathrm{~mL} \mathrm{H}_{2} \mathrm{O}$ ) was used for 6 to 10 seconds, depending on the zones of interest. Microstructural examination was carried out using both an optical microscope and a scanning electron microscope (SEM). An inverted optical microscope (Olympus GX710; Olympus America, Center Valley, PA) equipped with a digital camera (XC50; Olympus America) and AnalySIS Five image analysis software (Olympus America) was used for the measurement of the joint geometry. A Hitachi SU-8000 FE-STEM (Hitachi, Tokyo, Japan) was used to characterize the microstructural features. Some selected fracture surfaces were examined using a JEOL JSM840 SEM (JEOL Ltd., Tokyo, Japan) at $15 \mathrm{kV}$ with a probe current of $1 \mathrm{nA}$.

\section{Microindentation Hardness Measurement}

The Vickers microindentation hardness was measured using a Struers Duramin A-300 hardness tester (Struers A/S, Ballerup, Denmark) at a load of $500 \mathrm{~g}$, a dwell period of 15 seconds, and an interval of $0.2 \mathrm{~mm}$. It is noteworthy that according to ASTM E384-05, ${ }^{[14]}$ the spacing between two adjacent indentations must be at least three times the diagonal length of the indentation. Hence, the spacing between two adjacent indentations during hardness testing was selected to maximize the number of the hardness measurements in the narrow fusion zone and HAZ, while ensuring high accuracy in

Table II. Experimental Parameters Used in this Study

\begin{tabular}{|c|c|c|c|c|c|}
\hline Sample \# & $\begin{array}{l}\text { Thickness } \\
(\mathrm{mm})\end{array}$ & $\begin{array}{c}\text { Laser } \\
\text { Power }(\mathrm{kW})\end{array}$ & $\begin{array}{c}\text { Welding } \\
\text { Speed }\left(\mathrm{m} \cdot \mathrm{min}^{-1}\right)\end{array}$ & $\begin{array}{c}\text { Wire Feed } \\
\text { Rate }\left(\mathrm{m} \cdot \mathrm{min}^{-1}\right)\end{array}$ & $\begin{array}{l}\text { Postweld } \\
\text { Condition }\end{array}$ \\
\hline 1 & 3.2 & 3.0 & 1.69 & 1.58 & As welded \\
\hline 2 & & 3.0 & 1.69 & 1.58 & SRA \\
\hline 3 & & 3.0 & 1.69 & 1.58 & STA \\
\hline 4 & 5.1 & 4.0 & 1.0 & 1.5 & As welded \\
\hline 5 & & 4.0 & 1.0 & 1.5 & SRA \\
\hline 6 & & 4.0 & 1.0 & 1.5 & STA \\
\hline
\end{tabular}

SRA: stress relief annealing; STA: solution heat treatment followed by aging. 
the values with a sizeable indentation. Under the loading conditions applied in this work, the diagonal length of the indentation was approximately $50 \mu \mathrm{m}$; therefore, a spacing of $200 \mu \mathrm{m}(0.2 \mathrm{~mm})$ was used.

\section{E. Characterization of Tensile Properties}

Three or four tensile samples were prepared for each joint according to ASTM E8M-04. ${ }^{[15]}$ Two tensile samples for each joint were tested using a $250-\mathrm{kN}$ MTS testing frame with a digital image correlation (DIC) system (ARAMIS; Gesellschaft für Optische Messtechnik [GOM], Braunschweig, Germany). The remaining tensile samples were tested using a $250-\mathrm{kN}$ MTS testing frame equipped with a laser extensometer. All the tensile samples were tested at room temperature and at a constant crosshead rate of $2 \mathrm{~mm} \cdot \mathrm{min}^{-1}$ over a gage length of $25 \mathrm{~mm}$.

\section{Digital image correlation}

DIC is a noncontact optical technique that can measure full-field two-dimensional or three-dimensional

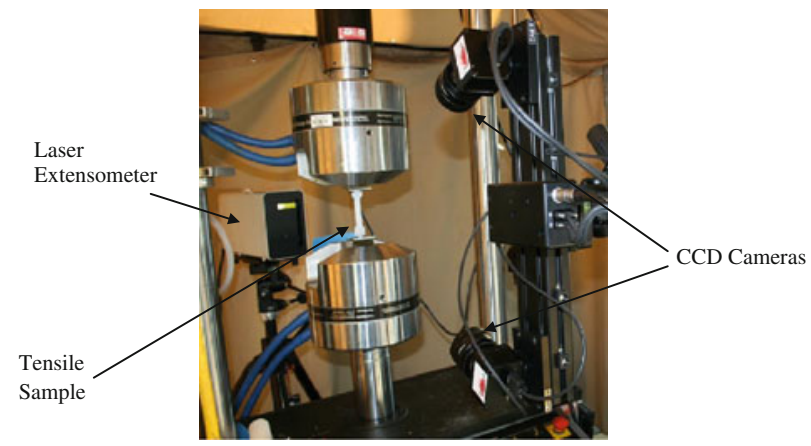

Fig. 1-A 3-D digital image correlation system integrated on a MTS testing frame. $C C D$, charge-coupled device.
(3-D) surface deformations. It is a highly responsive method with wide tolerances in sample size that requires a simple surface treatment on the test samples. ${ }^{\text {16-19] }}$ Two cameras are usually used for the 3-D DIC. Figure 1 shows a simple schematic of a 3-D DIC system where the orientations for the two cameras relative to the sample are indicated.

The surface treatment for DIC consists of applying a white color on the gage length of the sample, followed by spraying with a refined airbrush, resulting in black speckles onto the white background. ${ }^{[20-22]}$ The size of the random speckles is very important and usually is very fine, on the scale of 1 to $100 \mu \mathrm{m}$. The DIC algorithm searches for a one-to-one association of points (pixels) in the series of the images taken during the testing and calculates the deformation for each stage.

\section{RESULTS AND DISCUSSION}

\section{A. Weld Geometry}

Figure 2 shows the transverse sections of the laser welds in the as-welded, SRA, and STA conditions for both the 3.2-mm- and 5.1-mm-thick Ti-6Al-4V sheets. No significant differences in weld geometry were found between the as-welded and the two PWHT conditions.

\section{B. Defects}

Underfill and porosity were the two main defects as observed in the laser welds (Figure 2). Loss of the material from the top surface as a result of evaporation and expulsion of the molten material is most likely the main reason for the formation of the underfill defect during laser welding of Ti-6Al-4V. This finding is in agreement with previous results on laser welding of aluminum $^{[23]}$ and titanium alloys ${ }^{[9,24,25]}$ that have noted

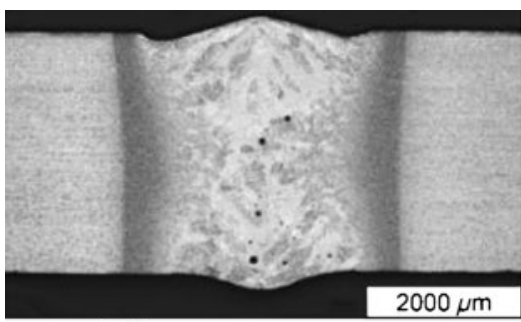

(a) As-welded (3.2 mm)

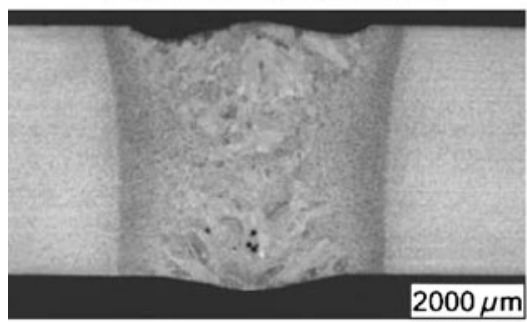

(d) As-welded (5.1 mm)

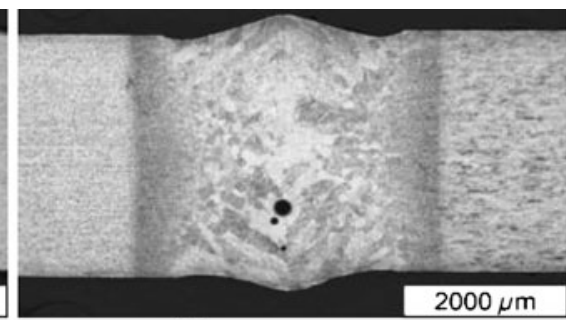

(b) SRA (3.2 mm)

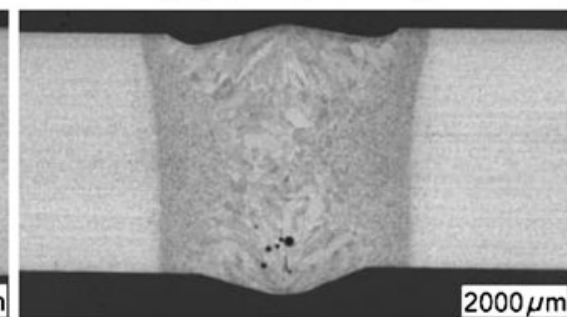

(e) SRA (5.1 mm)

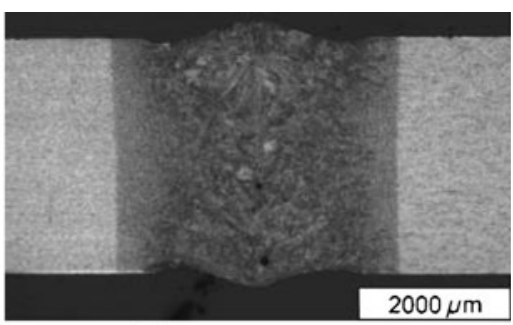

(c) STA $(3.2 \mathrm{~mm})$

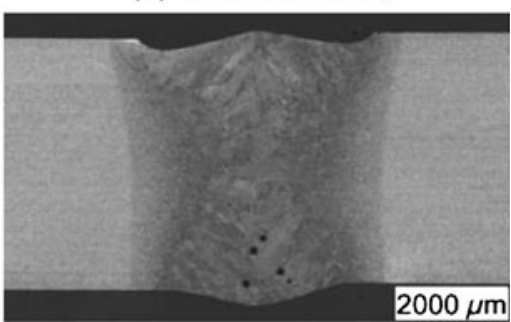

(f) $\mathrm{STA}(5.1 \mathrm{~mm})$

Fig. 2-Transverse sections showing as-welded, SRA, and STA conditions for ( $a$ through $c)$ 3.2-mm-thick and ( $d$ through $f)$ 5.1-mm-thick Ti-6Al-4V joints. 
the occurrence of underfill defects at a high laser power and/or low welding speed (i.e., high heat input) as a result of the increased losses from evaporation and/or spattering of the material. Although a high welding speed reduces the heat input, the faster cooling rate shortens the solidification time of the liquid metal in the fusion zone (FZ), which can lead to insufficient material refill into the weld groove and thus help the formation of an underfill defect. $^{[23]}$ The presence of underfill defects reduces the cross-sectional thickness of the weld, which leads to local stress concentration and "premature" crack formation that reduce the tensile and fatigue strengths of the welds. ${ }^{[26]}$ Figure 3 shows a typical top surface underfill defect for sample 5. According to AWS D17-1, ${ }^{[27]}$ the maximum underfill depth allowable in the weld is 7 pct of the sheet thickness, i.e., $0.22 \mathrm{~mm}$ and $0.36 \mathrm{~mm}$ for the 3.2-mm- and 5.1-mm-thick Ti-6Al-4V sheets, respectively. As the measured maximum underfill depths were $0.13 \mathrm{~mm}$ and $0.28 \mathrm{~mm}$ for the $3.2-\mathrm{mm}$ - and $5.1-\mathrm{mm}$-thick joints, respectively, the Ti-6Al-4V laser welds manufactured in this work met AWS D17-1 requirements.

Porosity is another main concern for laser welding of Ti-6A1-4V, as shown in Figure 4. Specifically, some scattered pores, usually located at the interface between the base metal and fusion zone, as well as pores at the centerline and the lower fusion zone, were observed. The mechanisms for the formation of porosity in titanium welds were dealt with in detail. ${ }^{[13]}$ It is mainly caused by the gas bubbles that are from the dissolved hydrogen and/or the entrapment during welding, which cannot escape before solidification. Another possible source for the formation of gas porosity is the contamination from grease, oil, and dirt on the surfaces of the weld pieces and/or filler material. ${ }^{[13,28,29]}$ For titanium joints, hydrogen is usually considered to be the primary source for the presence of gas porosity. ${ }^{[29]}$ The bubbles usually tend

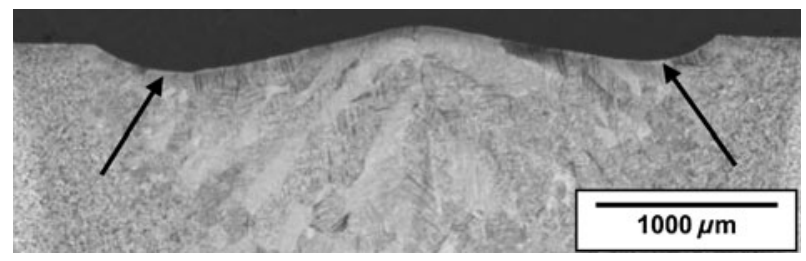

Fig. 3-Image of the top surface of sample 5 indicating typical underfill defect.

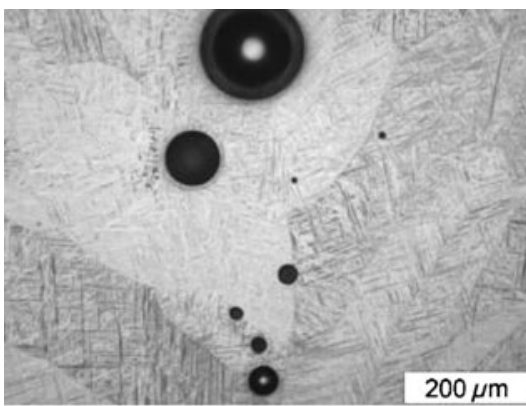

(a) $3.2 \mathrm{~mm}, \mathrm{SRA}$

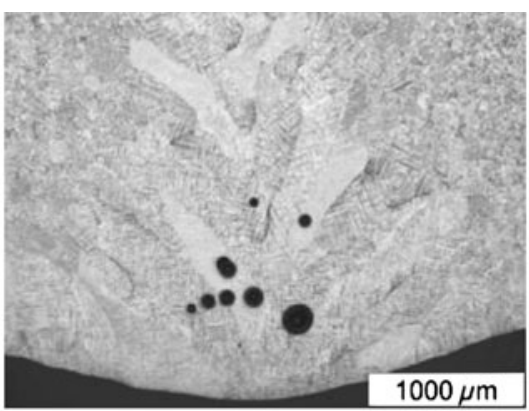

(b) $5.1 \mathrm{~mm}$, SRA to jump to hotter regions during solidification in most alloys. ${ }^{[30]}$ However, the solubility of hydrogen in liquid titanium decreases with increasing temperatures. Therefore, bubbles tend to migrate from the hot weld center to the cold fusion boundary in titanium welds, explaining the presence of porosity near the fusion boundary. During solidification, the dissolved hydrogen is usually rejected from the liquid and appears at the solid/liquid interface. The center zone will be the last region of the weld to solidify and, thus, is usually enriched with hydrogen. In addition, the hydrogen-rich liquid in the center region has a low temperature at the late stage of solidification, and hence, the gas cannot effectively escape, leading to the presence of porosity in the center of the welds. ${ }^{[13]}$ However, keyhole collapse may also contribute to porosity formation ${ }^{[7]}$ if a sudden drop in vapor pressure results in slumping of the molten metal into the keyhole. ${ }^{[31]}$ In particular, keyhole stability is related to the welding speed and the balance in forces acting on the keyhole wall (mainly vapor pressure and surface tension). ${ }^{[32]}$ Usually, a stable keyhole can be achieved at high welding speeds only. ${ }^{[33]}$ It is noteworthy that the pores caused by unstable keyholes are usually located in the lower half of the weld. ${ }^{[34,35]}$ The main concern related to the presence of porosity is a reduction in the weld cross-sectional area, especially when a large number of pores concentrated in one region can coalesce into large pores. Inevitably, the presence of porosity degrades the mechanical properties of the joints, usually affecting the ductility to a greater extent than the tensile strength. In this study, it was observed that the total percent porosity remained relatively low, 0.58 pet and 0.42 pct ( $<1$ pct area of the fusion zone) for the $3.2-\mathrm{mm}$ and $5.1-\mathrm{mm}$ joints, respectively. Lower porosity in the 5.1-mm welds is caused by its flotation and escape at the lower cooling rate as experienced in the thicker joints.

\section{Microstructure}

Figure 5 shows the base metal (BM) microstructures for the two sheet thicknesses in the as-received, SRA, and STA conditions. The as-received BM microstructure of the 3.2-mm-thick Ti-6Al-4V sheet (Figure 5(a)) consisted of equiaxed $\alpha$ grains with intergranular $\beta$, whereas the $5.1-\mathrm{mm}$ sheet consisted of equiaxed primary $\alpha$ grains and equiaxed transformed $\beta$ grains with a coarse lamellar $\alpha+\beta$ structure (Figure 5(b)). The

Fig. 4-Typical porosity observed in the welds; The spherical shape of the pores indicates that these are most likely gas induced. 


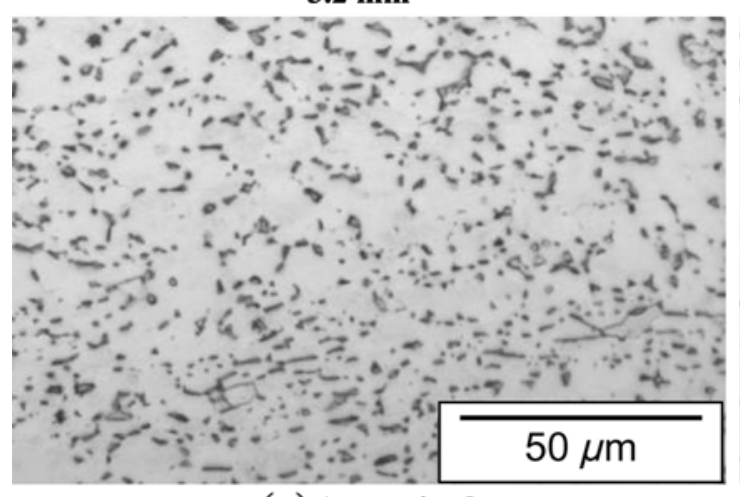

(a) As-received

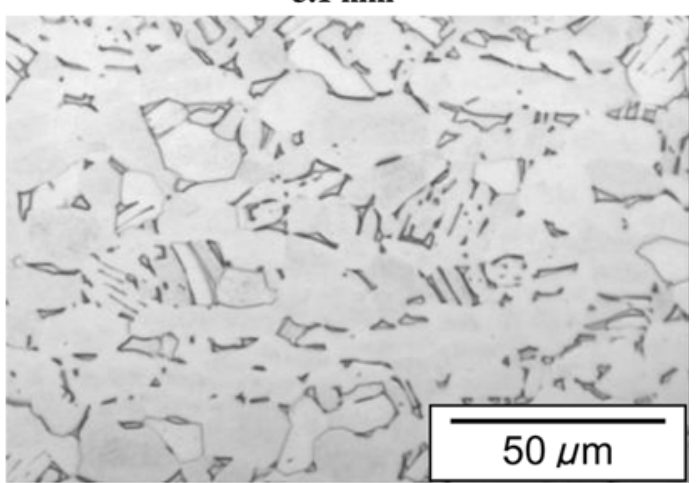

(b) As-received

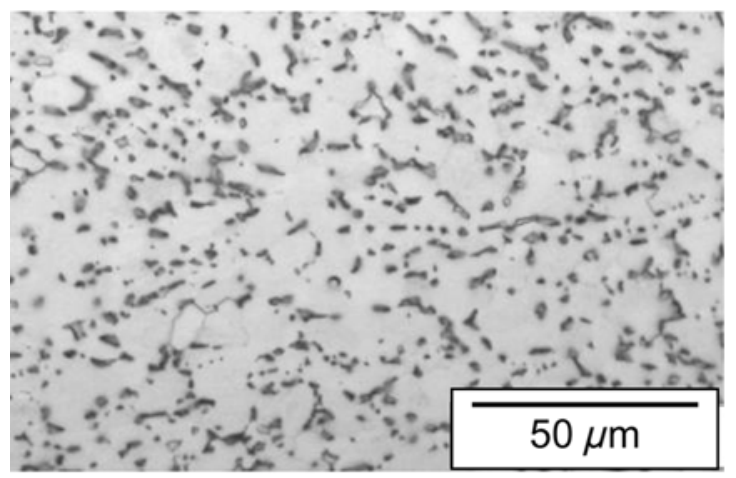

(c) SRA

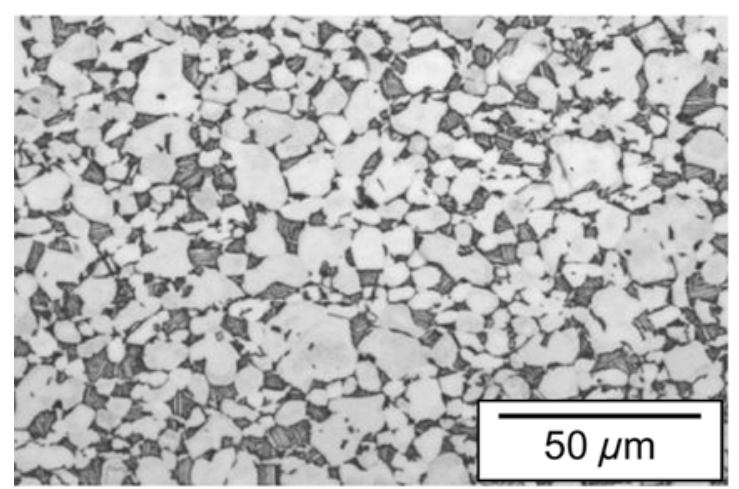

(e) STA

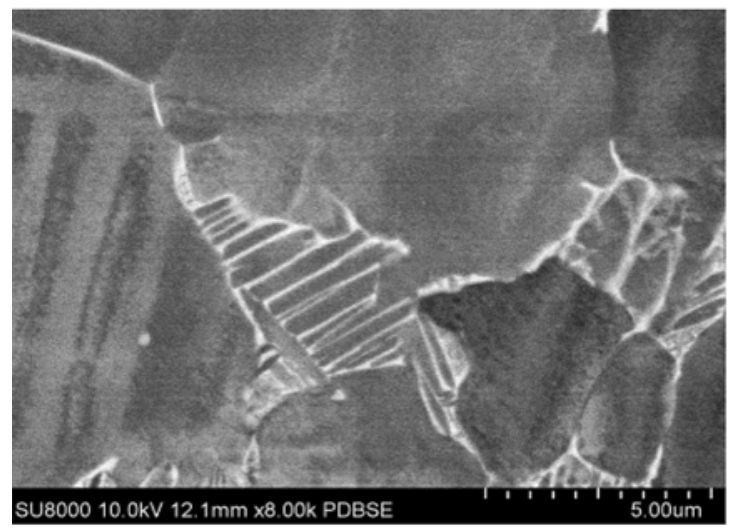

(g) STA

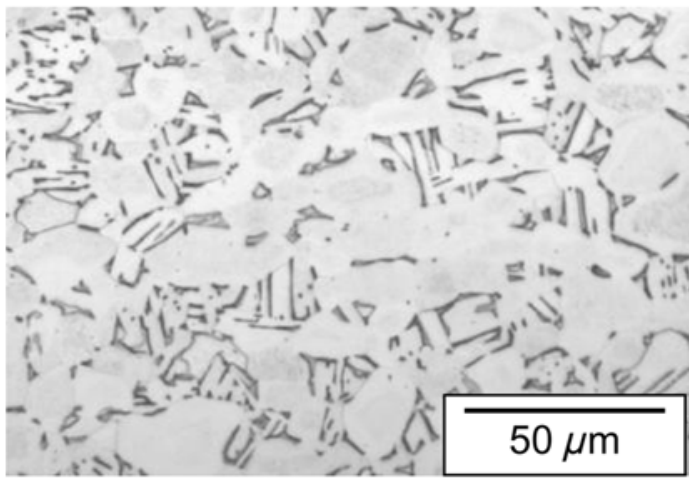

(d) SRA

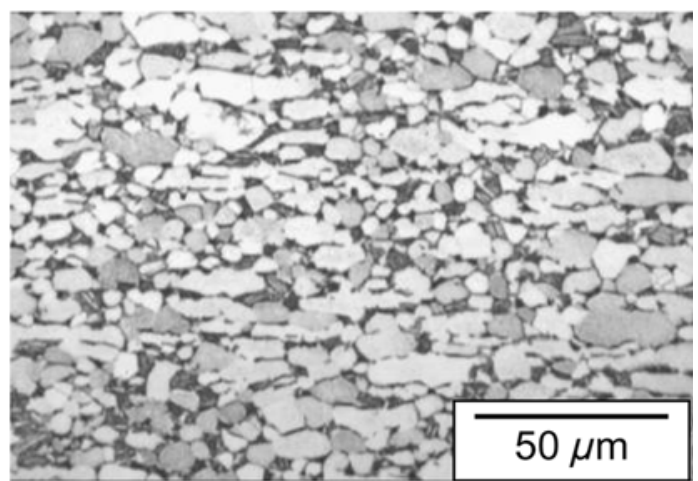

(f) STA

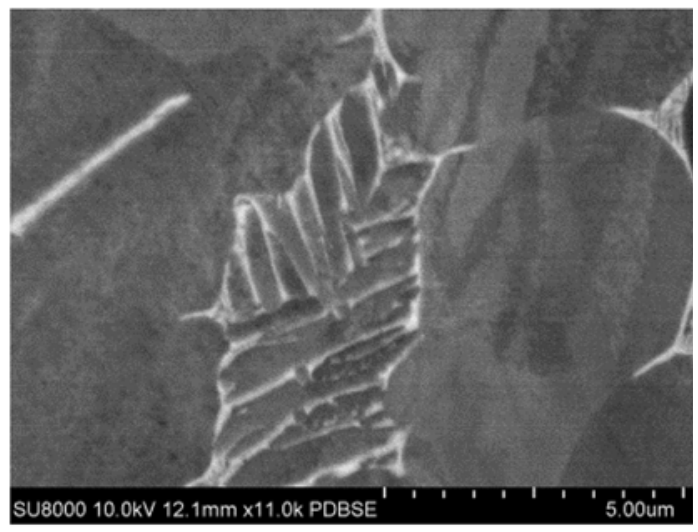

(h) STA

Fig. 5-Base metal microstructures in the as-received, SRA, and STA conditions for 3.2-mm and 5.1-mm sheets. 
application of a SRA treatment showed no significant changes relative to the as-received $\mathrm{BM}$ microstructure under the microscope for the two sheet thicknesses (Figures 5(c) and (d)). However, STA (Figures 5(e) and (f)) was observed to change the BM microstructure from the as-received condition to a structure consisting of fine primary equiaxed $\alpha$ (white regions) and fine transformed $\beta$ grains (dark regions in optical microscope image). High-magnification images using SEM reveal the presence of a fine interlamellar $\alpha+\beta$ structure within the "dark" transformed $\beta$ grains of the BM microstructure in the STA condition (Figures 5(g) and (h)).

For the two sheet thicknesses welded in the current study, the macrostructural and microstructural constituents of the HAZ and FZ, as observed by using optical microscopy, were similar. The FZ macrostructure of the Ti-6Al-4V laser welds (Figure 2) is characterized by columnar prior- $\beta$ grains that epitaxially grow from the semimelted $\beta$ grains in the near-HAZ and impinge at the weld centerline after solidification. Figures 6 and 7 show the microstructural characteristics of the FZ and HAZ in the as-welded, SRA, and STA conditions for the 3.2-mm and 5.1-mm welds, respectively. Within the prior- $\beta$ grains, the FZ microstructure seemed to consist of martensite (diffusionless), or a combined structure of both martensitic and Widmanstätten (diffusional) $\alpha$ in the as-welded conditions, as shown in Figures 6(a) and (b), which is expected for the transformed $\beta$ phase under the rapid solidification conditions typical of laser welding. It is interesting to note the formation of a thin $\alpha$ phase layer at the prior- $\beta$ grain boundaries in the as-welded condition for the 5.1-mm welds (Figure 6(b)) but not for the 3.2-mm joints (Figure 6(a)). The precipitation of grain boundary $\alpha$ phase is usually observed at a cooling rate less than $683 \mathrm{~K} / \mathrm{s}\left(410{ }^{\circ} \mathrm{C} / \mathrm{s}\right){ }^{[36]}$ Titanium has a low heat conductivity coefficient and, thus, has a relatively low cooling rate during solidification, particularly for the thicker $(5.1 \mathrm{~mm})$ section. The appearance of a thin grain boundary $\alpha$ phase layer along the prior- $\beta$ grain boundaries in the FZ of the 5.1-mm-thick welds suggests that the cooling rate is slightly less than $683 \mathrm{~K} / \mathrm{s}$ $\left(410{ }^{\circ} \mathrm{C} / \mathrm{s}\right)$ during cooling after laser welding. In contrast, the absence of the grain boundary $\alpha$ phase along the prior- $\beta$ grain boundaries in the FZ of the 3.2-mmthick welds suggests that the cooling rate after laser welding is greater than $683 \mathrm{~K} / \mathrm{s}\left(410{ }^{\circ} \mathrm{C} / \mathrm{s}\right)$. Hence, considering that the critical cooling rate for displacive to diffusional transformation is approximately $683 \mathrm{~K} / \mathrm{s}$ $\left(410^{\circ} \mathrm{C} / \mathrm{s}\right)$ in Ti-6Al-4V, ${ }^{[36]}$ the FZ of the $5.1-\mathrm{mm}$-thick welds most likely consists of more Widmanstätten $\alpha$ relative to the 3.2-mm-thick welds, which may be mostly martensitic. Previous work on electron beam welding of Ti-6Al-4V $\mathrm{V}^{[37]}$ has indicated that increasing the fraction of Widmanstätten relative to martensitic $\alpha^{\prime}$ improves the ductility.

From optical microscopy, no significant differences in the FZ bulk microstructure were observed between the as-welded (martensite or a combined structure of both martensitic and Widmanstätten $\alpha$ in Figures 6(a) and (b)) and the SRA (tempered structure in Figures 6(c) and (d)) conditions, which is in agreement with the previous work on electron beam welding of Ti-6Al-4V. ${ }^{[38]}$
However, the microstructure of the transformed $\beta$ grains in the FZ after STA (Figures 6(e) and (f)) consisted mainly of coarse $\alpha$ platelets with interlamellar $\beta$, which is an inevitable result of the preferred growth of $\alpha$ platelets during the solution treatment of the sample at a relatively high temperature below the $\beta$ transus. After SRA, the grain boundary $\alpha$ in the $5.2-\mathrm{mm}$ welds becomes slightly fragmented, indicating its partial dissolution during the long holding at $811 \mathrm{~K}\left(538{ }^{\circ} \mathrm{C}\right)$ during SRA. During the solution heat treatment at a temperature $(1186 \mathrm{~K}$ $\left[913{ }^{\circ} \mathrm{C}\right]$ in this study) below the $\beta$ transus $(1253 \mathrm{~K}$ $\left.\left[980^{\circ} \mathrm{C}\right]\right)$, the grain boundary $\alpha$ phase may not fully been transformed into $\beta$, but it will be incorporated with the $\alpha$ platelets in the transformed $\beta$ during the cooling and aging that follow. Thus, retained grain boundary $\alpha$ is difficult to identify in the fusion zone in the STA condition (Figure 6(f)).

In $\mathrm{Ti}$ alloy welds, the HAZ is usually classified into two subregions, i.e., near-HAZ and far-HAZ $\left(<T_{\beta}\right)$. The near-HAZ region experienced a temperature ranging from $T_{\beta}$ to the liquidus and hence, a similar structure to the FZ is expected after laser welding. In contrast, the far-HAZ region consisted of a mixture of the microstructural constituents in both the FZ and the BM, as shown in Figure 7. For the as-welded and SRA samples, the near-HAZ microstructure consisted entirely of the transformed $\beta$ grains with martensite $\alpha^{\prime}$ or a combined structure of both martensitic and Widmanstätten $\alpha$ structures (tempered for the SRA). With increasing distance away from the FZ boundary, the fraction of martensitic and Widmanstätten $\alpha$ in the far-HAZ region decreased and increasing remnants of the BM constituents were observed, namely (1) equiaxed primary $\alpha$ with intergranular $\beta$ for the 3.2-mm-thick welds and (2) equiaxed primary $\alpha$ and equiaxed transformed $\beta$ grains with a lamellar $\alpha+\beta$ structure for the 5.2-mmthick welds. For the STA weld, the near-HAZ region also has a microstructure similar to the fusion zone, consisting almost entirely of the transformed $\beta$ grains with a lamellar $\alpha+\beta$ structure. In the far-HAZ region of the STA samples, with increasing distance from the FZ boundary, the fraction of the transformed $\beta$ (with a lamellar $\alpha+\beta$ structure) decreased, whereas the primary equiaxed $\alpha$ fraction increased.

\section{Microindentation Hardness}

Figure 8 shows the three different hardness profiles of the as-welded, SRA, and STA conditions for the two sheet thicknesses. Also, the variations in average hardness values for the BM, HAZ, and FZ in the as-welded, SRA, and STA conditions are shown in Figure 9. In the as-welded condition, the maximum average hardness value $(\sim 350 \mathrm{HV})$ occurs in the FZ and the near-HAZ, and the hardness in the far-HAZ decreases from approximately $350 \mathrm{HV}$ to approximately $310 \mathrm{HV}$, the $\mathrm{BM}$ hardness value. The occurrence of a maximum hardness in the FZ and near-HAZ is related to the formation of martensitic and Widmanstätten $\alpha$ structure and is consistent with the previous work that was reported to be approximately 360 to $370 \mathrm{HV}$ in the FZ 
$3.2 \mathrm{~mm}$

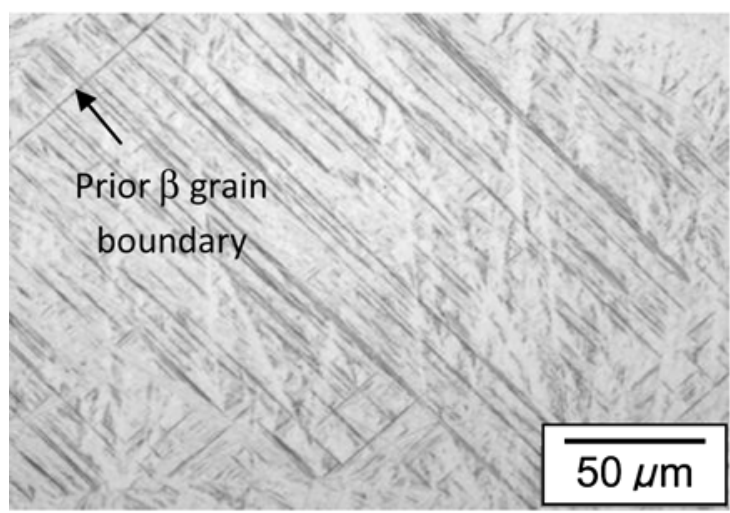

(a) As-welded

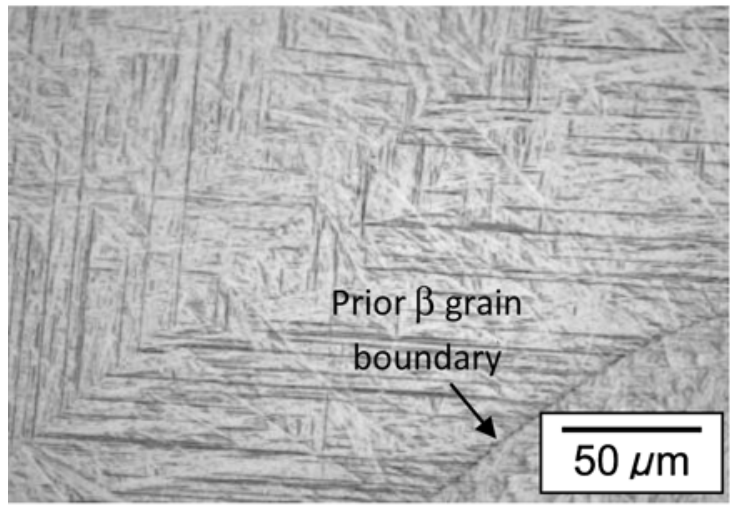

(c) SRA

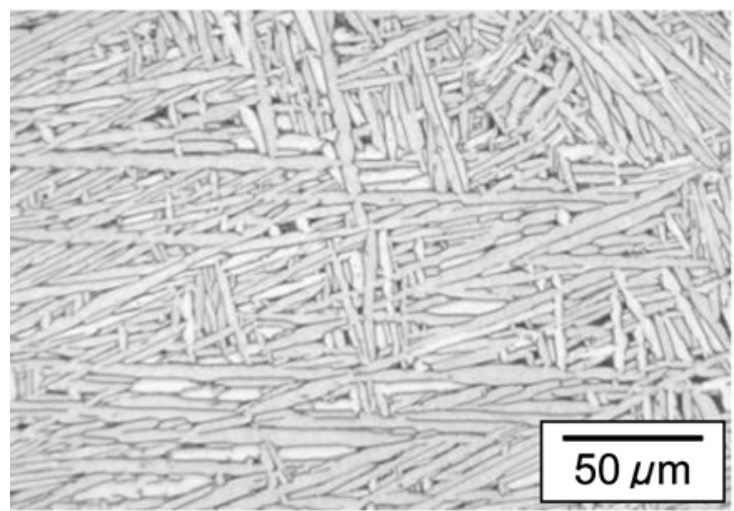

(e) STA
$5.1 \mathrm{~mm}$

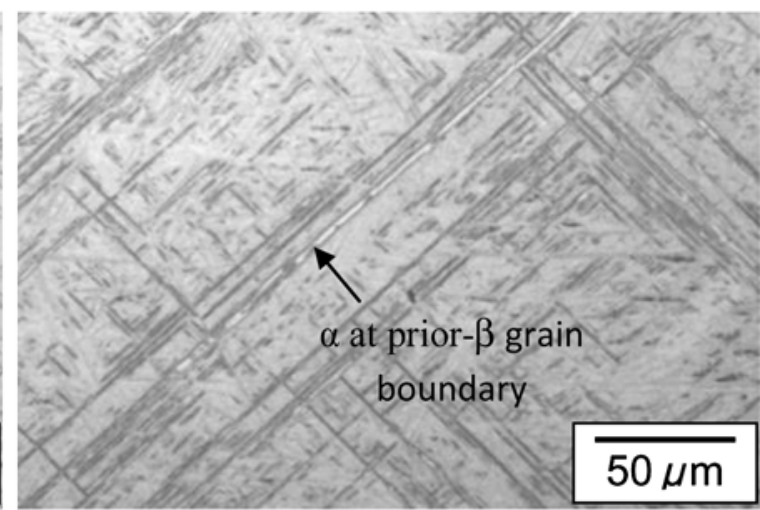

(b) As-welded

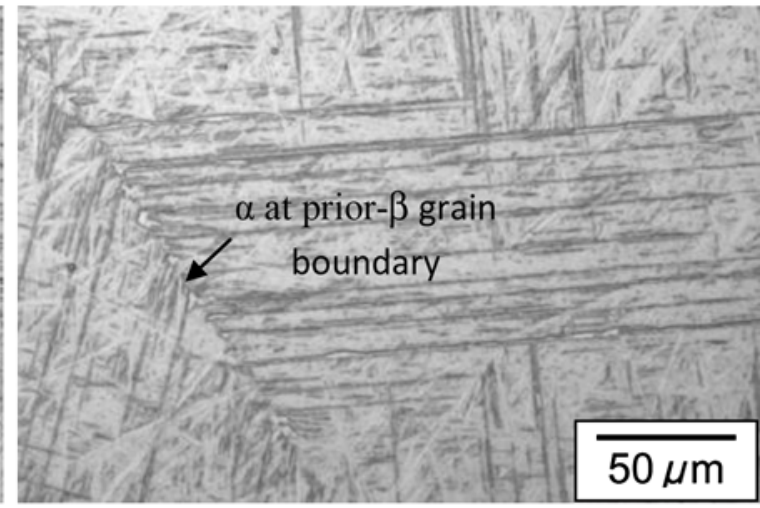

(d) SRA

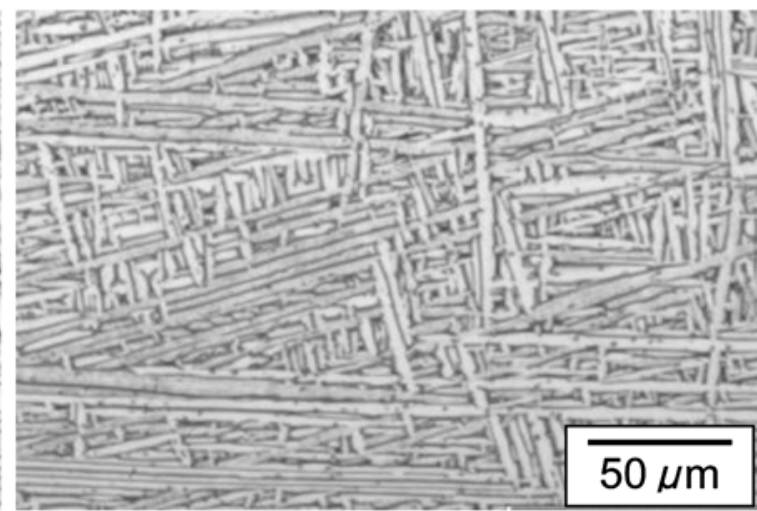

(f) STA

Fig. 6-FZ microstructure at as-welded, SRA, and STA conditions for the two sheet thicknesses.

of the laser or electron beam welded Ti-6Al-4V with a thickness of $3.2 \mathrm{~mm} .^{[37,39]}$ With increasing distance from the FZ boundary, the hardness values in the farHAZ decrease because the fraction of martensitic and Widmanstätten $\alpha$ in the microstructure decreases.

A similar microhardness profile was observed for the SRA condition for both sheet thicknesses. However, the average hardness of the FZ increased by approximately 3.8 pct and 3.9 pet in the SRA condition compared with the as-welded condition for the 3.2 and $5.1-\mathrm{mm}$ thick samples, respectively. The increase in hardness as observed for the two sheet thicknesses after SRA is in agreement with the previous work that reported an increase of 4 pct for the FZ of the laser-welded Ti-6Al$4 \mathrm{~V}$ after SRA at $823 \mathrm{~K}\left(550{ }^{\circ} \mathrm{C}\right)$ for 3 hours. ${ }^{[39]}$ The increase in hardness has been attributed to the partial decomposition of $\alpha^{\prime}$ to $\alpha+\beta$ after SRA. Also, noting that vanadium is a $\beta$-stabilizer that renders the finishing temperature for $\alpha^{\prime}$ formation $\left(\mathrm{M}_{\mathrm{f}}\right)$ below room temperature, some retained $\beta$ possibly still exists in the $\mathrm{FZ}$ of the weldments. In this case, the microprecipitation of the $\alpha$-phase platelet from the transformation of the retained $\beta$ can also occur during SRA. Because the $\beta$-phase is comparatively soft and ductile relative to the $\alpha$-phase, as SRA progresses and the amount of $\beta$ decreases, the hardness in the FZ and the HAZ increases. ${ }^{[40,41]}$ 
$3.2 \mathrm{~mm}$

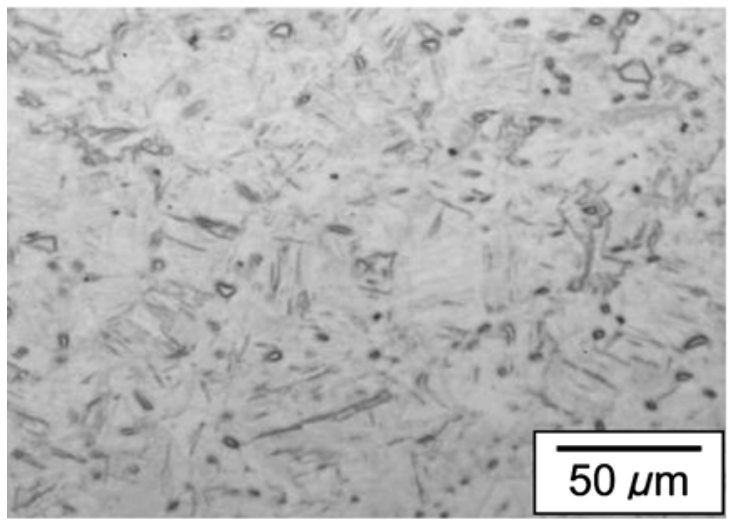

(a) As-welded

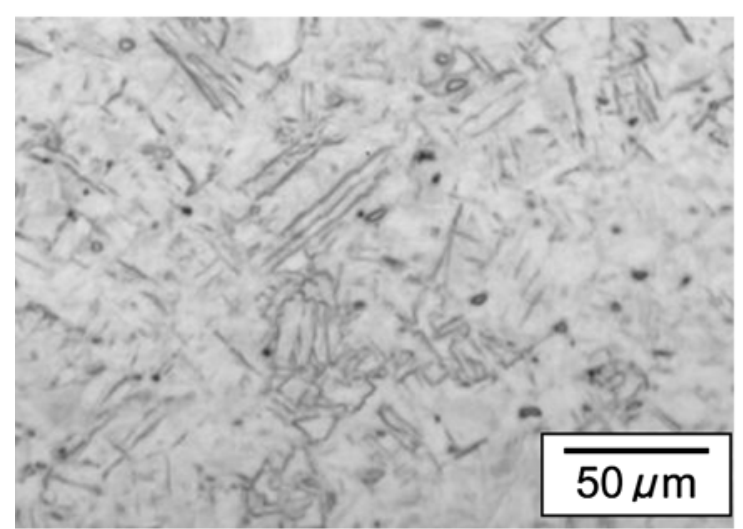

(c) SRA

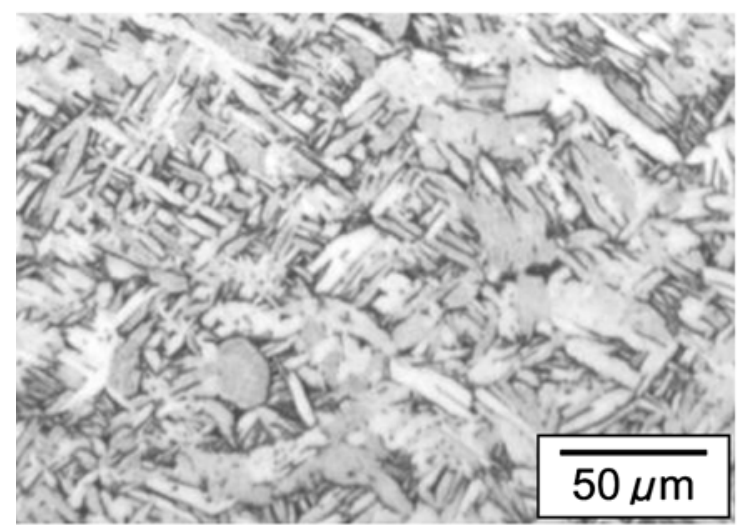

(e) STA

\section{$5.1 \mathrm{~mm}$}

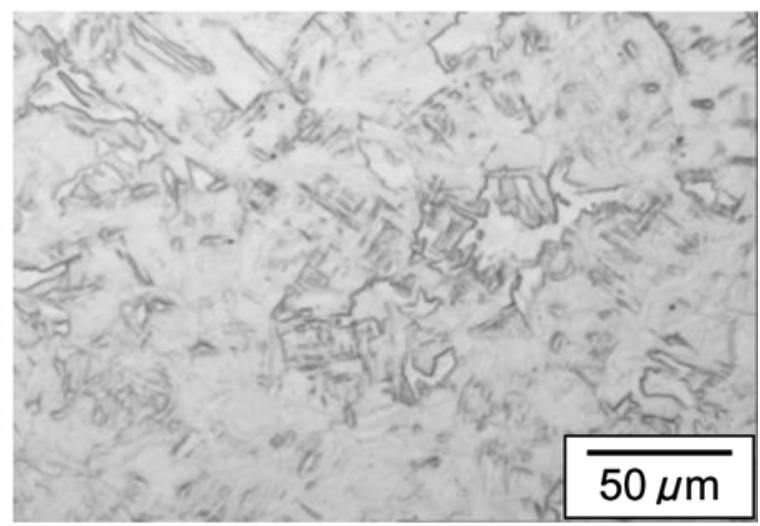

(b) As-welded

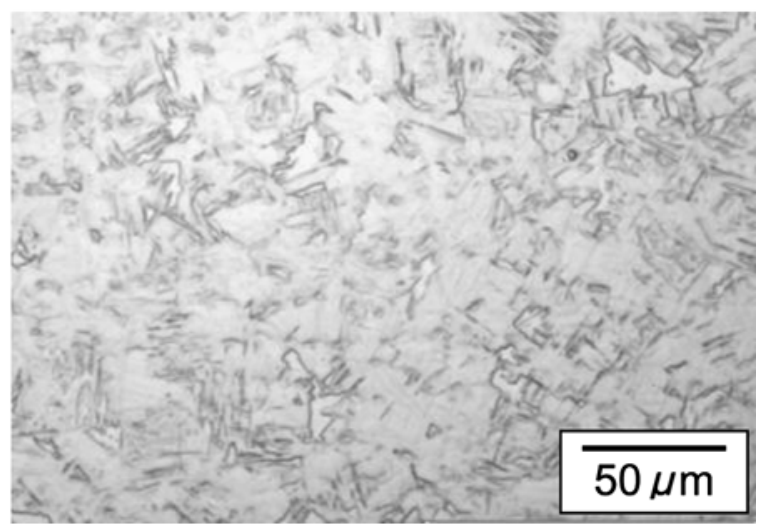

(d) SRA

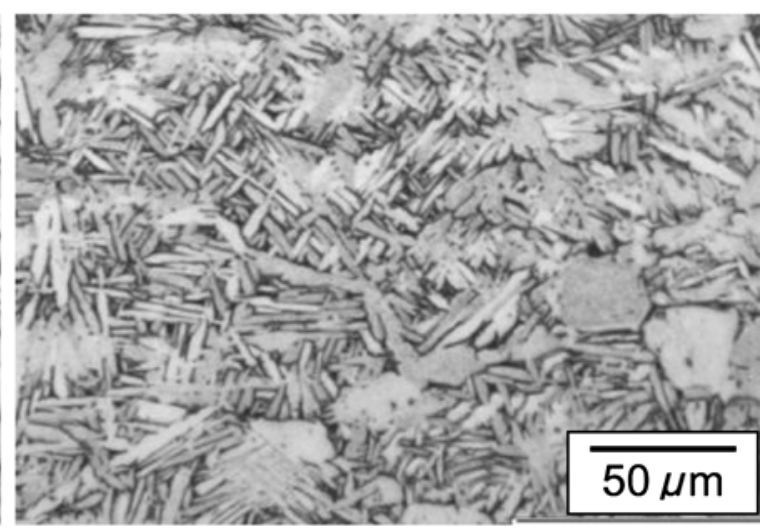

(f) STA

Fig. 7-Middle far-HAZ microstructures in as-welded, SRA, and STA conditions for the two sheet thicknesses.

For the STA condition, the coarse lamellar $\alpha-\beta$ structure in the FZ exhibited a low hardness value, nearly that of the primary equiaxed $\alpha$ and transformed $\beta$ microstructure of the BM. In particular, the FZ average hardness decreased approximately 6.6 pct and 5.3 pct in the STA condition compared with the as-welded condition for the 3.2-mm- and 5.1-mm-thick samples, respectively. The decrease in hardness is related to the coarse interlamellar $\alpha-\beta$ structure that has lower hardness than martensitic and Widmanstätten $\alpha$. As a whole, the hardness in the BM did not change under the PWHT conditions applied in this study. However, the hardness in the FZ nearly decreased to that of the BM after STA.

\section{E. Global Tensile Properties}

Table III shows the failure locations and the average joint efficiencies for the as-welded, SRA, and STA conditions. Joint efficiency is defined as the percentage of the ultimate tensile strength of the welded sample to that of the base material. The connotation of " 3 BM" for the failure location in Table III implies that three 


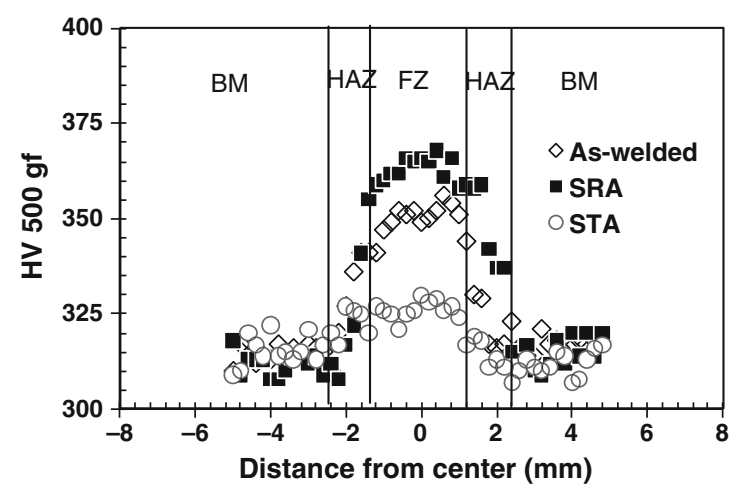

(a) $3.2 \mathrm{~mm}$

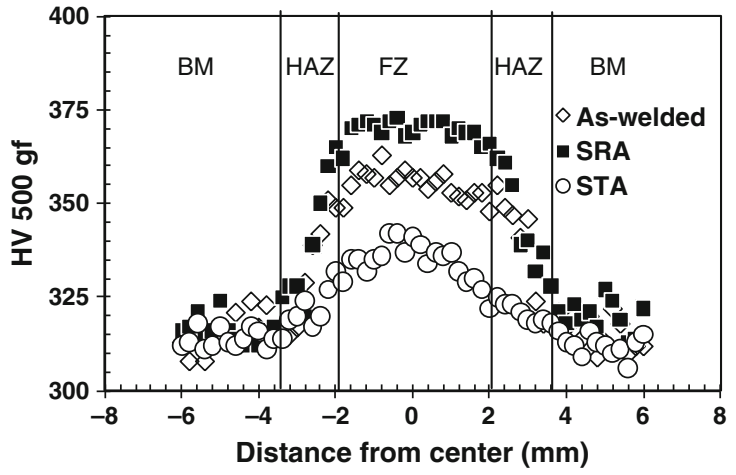

(b) $5.1 \mathrm{~mm}$

Fig. 8-Hardness distributions for the 3.2-mm- and 5.1-mm-thick welds in the as-welded, SRA, and STA conditions. (The narrow near-HAZ is included in the FZ because of the similar microstructure.).

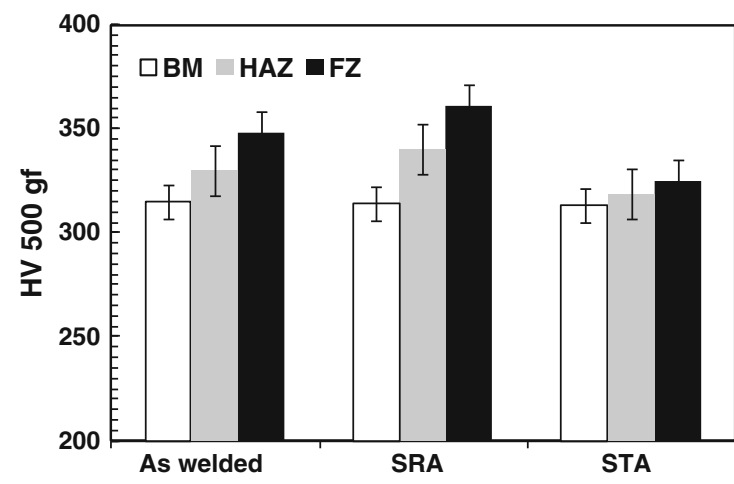

(a) $3.2 \mathrm{~mm}$

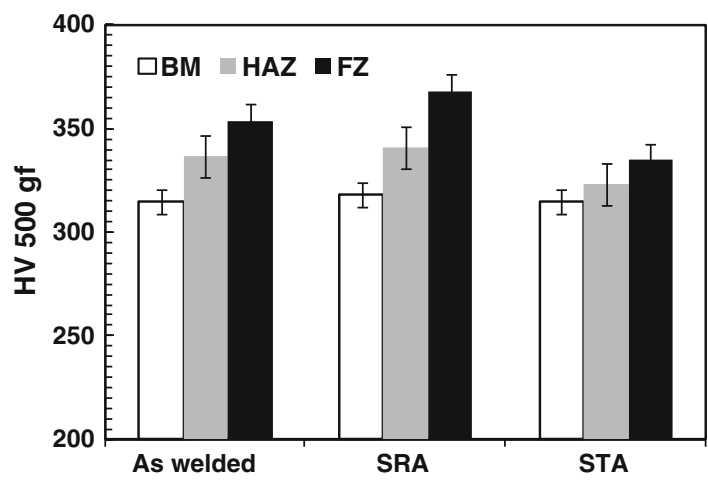

(b) $5.1 \mathrm{~mm}$

Fig. 9-Average hardness of the three different zones in as-welded, SRA, and STA conditions: (a) 3.2-mm- and (b) 5.1-mm-thick samples.

Table III. Failure Locations and Average Joint Efficiencies

\begin{tabular}{llcc}
\hline Thickness & $\begin{array}{c}\text { Sample } \\
\text { Condition }\end{array}$ & $\begin{array}{c}\text { Failure } \\
\text { Location }\end{array}$ & $\begin{array}{c}\text { Joint } \\
\text { Efficiency (pct) }\end{array}$ \\
\hline 3.2 & As welded & $3 \mathrm{BM}$ & 100 \\
& SRA & $3 \mathrm{BM}$ & 100 \\
5.1 & STA & $3 \mathrm{FZ}$ & 95 \\
& As welded & $3 \mathrm{BM}$ & 100 \\
& SRA & $3 \mathrm{BM}$ & 100 \\
& STA & $4 \mathrm{HAZ}$ & 95 \\
\hline
\end{tabular}

tensile samples were tested and all failed in the BM. The FZ of the as-welded and the annealed samples for both thicknesses remained stronger than the BM, resulting in the tensile failure in the BM. However, the STA samples mainly fractured in the FZ for 3.2-mm-thick samples because of the presence of porosity as well as the coarse interlamellar $\alpha-\beta$ structure. Crack formation occurred at the underfill defect (maximum $0.13 \mathrm{~mm}$ ) because of strain concentration and propagated through the FZ because of the presence of many pores as observed on fracture surface (as shown in Figure 11). Heating of the sample to $1186 \mathrm{~K}\left(913{ }^{\circ} \mathrm{C}\right)$ during the solution heat treatment may have resulted in hydrogen diffusion into the existing porosity because of the lower hydrogen solubility of Ti-6Al-4V at higher temperatures, thereby rendering a slight expansion of the pores in the FZ. However, these pores observed on the fracture surface are mainly precipitated during laser welding. The STA samples of the 5.1-mm thickness failed through the HAZ because of the presence of the underfill defect (maximum $0.28 \mathrm{~mm}$ ) as well as the presence of the weak interlamellar $\alpha-\beta$ structure in the HAZ. The 5.1-mm welds have slightly lower porosity and a higher FZ hardness than the 3.2-mm joints (Figure 8), favoring the crack propagation in the HAZ. PWHT (SRA or STA) has no influence on the underfill depth but the underfill defect serves as an initiation site for crack formation when the BM is strong.

Figure 10 shows the variations of the global tensile properties for the two thicknesses. The global tensile properties (yield stress [YS], ultimate tensile stress [UTS], and El. pct) are similar for the as-welded and SRA welds for both thicknesses. However, a reduction in yield and ultimate tensile stress was observed for the STA samples (Figures 10(a) and (b)) as a result of the transformation of stronger martensitic and Widmanstätten $\alpha$ structures to a relatively weaker interlamellar $\alpha-\beta$ structure. Elongation at fracture (El pct) indicated in Figure 10(c) also decreased for the STA condition compared with the as-welded and SRA conditions. Particularly, the strain localization starts in the area of the underfill defect rather than in the more ductile BM. 


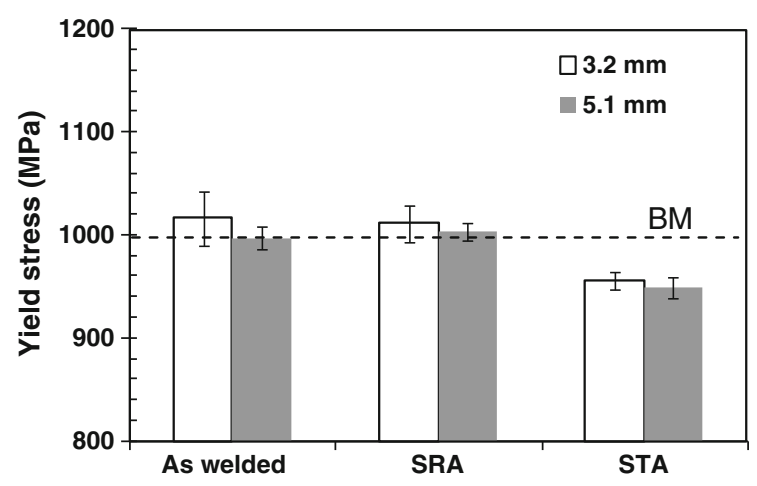

(a)

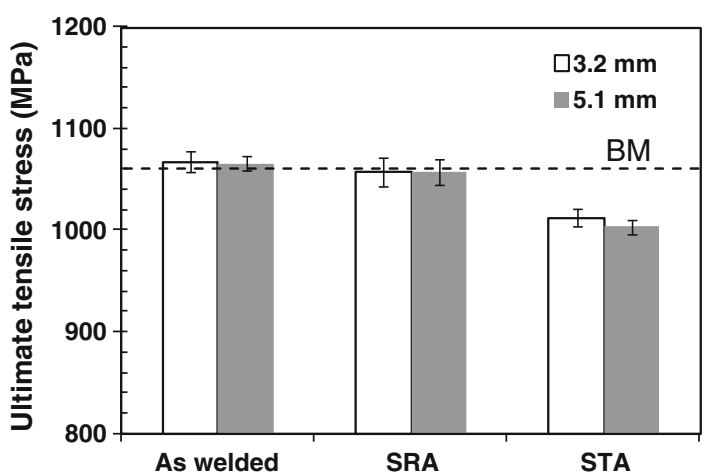

(b)

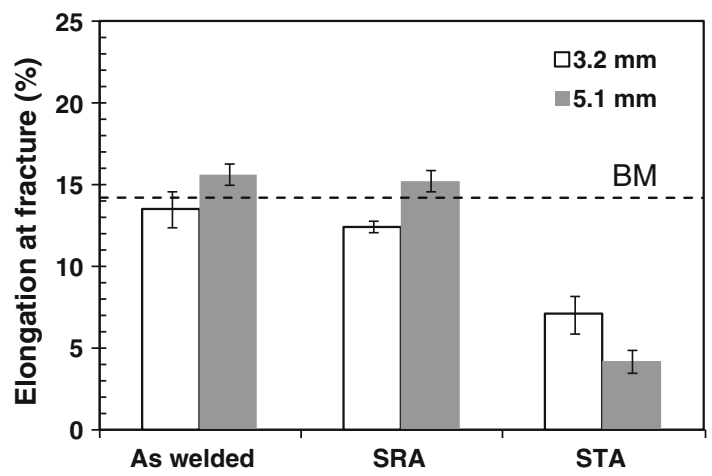

(c)

Fig. 10-Variations of global tensile properties: (a) yield stress, (b) ultimate tensile stress, and (c) elongation at fracture in the as-welded, SRA, and STA conditions for the two sheet thicknesses.

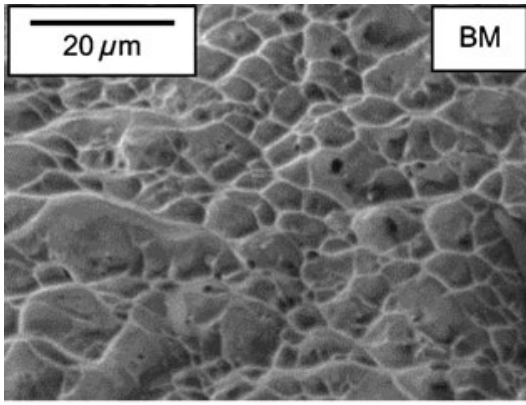

As welded

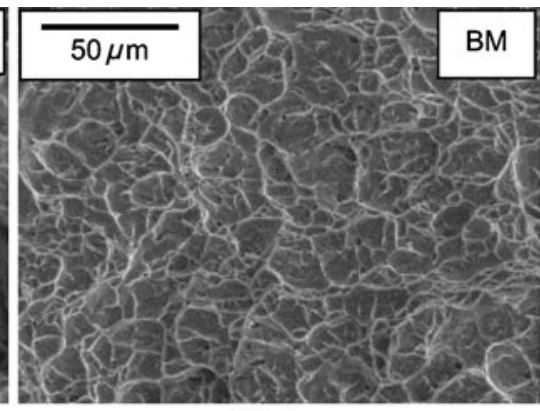

SRA

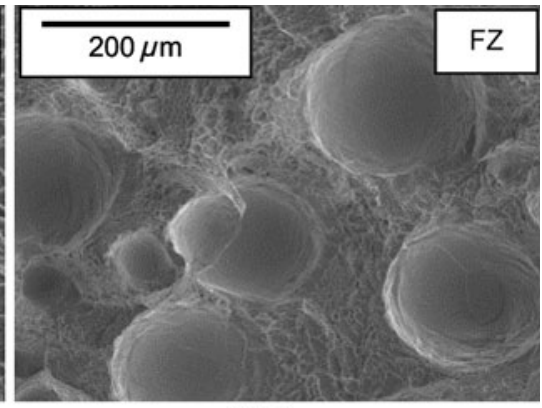

STA

Fig. 11-SEM images indicating the fracture surfaces of the 3.2-mm-thick samples.

The crack may then propogate quickly through the HAZ or FZ and lead to premature tensile failure in the HAZ or FZ with a significantly reduced plastic deformation compared with the as-welded and SRA conditions. Although the average joint efficiency in terms of tensile strength is maximum for the as-welded condition and minimum for the STA condition (Table III), the three conditions (as-welded, SRA, and STA) exhibited an efficiency in the joint strength of nearly 100 pct. Despite the yield strength and ultimate tensile strength values being comparable with that of the $\mathrm{BM}$, the laser welds exhibited a significant loss in ductility after STA. It is noteworthy that a comparison of the as-welded properties of the $3.2-\mathrm{mm}$ - and 5.1-mm-thick welds indicated a higher elongation at fracture for the latter, which supports the premise of a greater fraction of diffusional $\alpha$ in the FZ because of the slower cooling rate after laser welding of the thicker section.

The SEM fractographic images reveal cup and cone fractures with dimpled structures for the as-welded, SRA, and STA conditions in both sheet thicknesses, thus indicating that ductile fracture occurred through coalescence of microvoids (Figures 11 and 12). The STA condition for the 3.2-mm-thick sample shows the presence of many pores in the FZ that have probably formed during welding and thus already existed in the joint before the heat treatment. The heat treatment may slightly expand the size of the porosity, but it is unlikely 


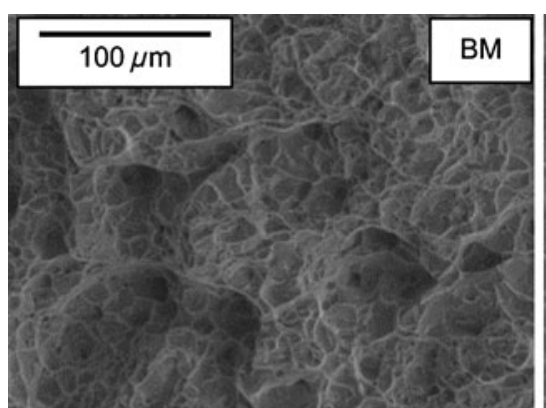

As welded

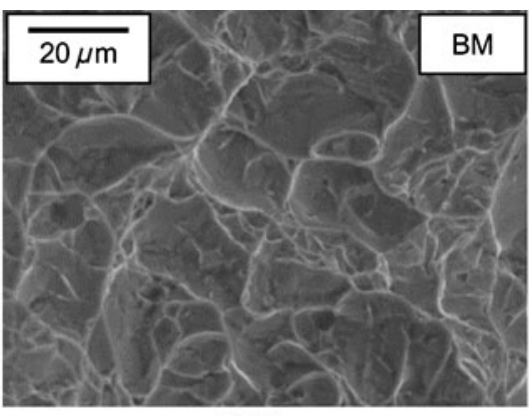

SRA

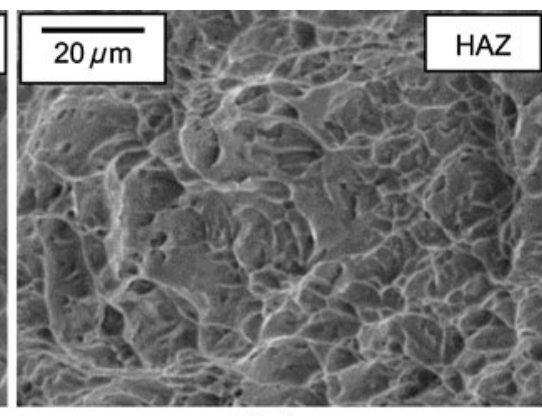

STA

Fig. 12-SEM images indicating the fracture surfaces of the 5.1-mm-thick samples.

to increase significantly the total amount of porosity. The failure location (i.e., BM, FZ, or HAZ) is indicated at the right top corner of each image.

\section{F. Local Tensile Properties}

The weld joint is a "composite" with three different zones that comprise of various microstructures. Thus, it is expected that the three zones will show different mechanical properties as expected from the microindentation hardness results (Section III-C). Using the ARAMIS system, it is possible to capture digital images at different stages of the tensile testing. In other words, the evolution of the deformation along the gage length of the tensile samples is recorded during tensile testing. Figure 13 shows the digital images extracted for the major strain just before the fracture for the as-welded, SRA, and STA conditions for both thicknesses. The gradients in color (or shading) indicate different strains prior to failure. From the acquired images, it is possible to create any size and any number of gage lengths and then determine stressstrain diagrams over a given gage length. Once the stressstrain diagram is discerned, it is possible to determine the yield stress and the localized plastic strain at fracture for a given location. These properties are termed "local tensile properties" in this study.

The images acquired by DIC were processed to understand the localized stress-strain response of the as-welded, SRA, and STA conditions. Specifically, an iso-stress condition (e.g., the same global stress at all locations) was assumed for each sample, similar to that employed by other researchers that have studied the local tensile properties in different welded alloys. ${ }^{[21,22]}$ After extracting the local strain data from the DIC images, it was then plotted against the corresponding global stress data to generate the localized stress-strain response of the sample. It is obvious from the DIC images that the strain concentration is maximum in the BM for the as-welded and SRA conditions for both thicknesses (Figure 13), indicating that the BM is the weakest region. Despite the presence of the underfill and porosity defects, the strain localization is minimum in the FZ where the martensitic and Widmanstätten $\alpha$ structure provides strengthening, although at the expense of ductility. Therefore, it is apparent that the strengthening effect of the microstructure in the FZ compensates for any weakening caused by the underfill and/or porosity defects in the as-welded and SRA conditions. For the STA condition of the 3.2-mm-thick weld, the maximum localized strain is in the underfill region, but the fracture was located in the FZ. This finding suggests that facture initiated from the underfill defect but propagated through the FZ where a cluster of porosities (Figure 11) and coarse interlamellar microstructure caused localized weakening that permitted an easier path for crack propagation. However, the STA condition of the 5.1-mm-thick weld showed that though the maximum strain localization is still in the underfill region where the crack forms, propagation is through the HAZ, mostly likely because of the lower extent of the porosity and higher hardness in the FZ than the 3.2-mm-thick welds.

Figure 14 shows the trends in the local tensile properties at fracture. The maximum plastic strain is observed to be located at the positions of fracture (Figures 14(a) and (b)) except for the STA condition in the 3.2-mm-thick sheet that failed in the FZ because of the porosity and/or microstructural coarsening as mentioned. The as-welded and SRA conditions failed in the $\mathrm{BM}$, resulting in the maximum localized plastic strains in the BM. Also, the FZ in the as-welded and SRA conditions shows the minimum localized plastic strain because of the presence of the strong and less ductile martensite. The localized plastic strains in the STA condition for the $3.2-\mathrm{mm}$ and 5.1-mm-thick welds, just before fracture, show that the maximum strain occurs at the underfill regions validating the propensity for crack formation in this region. Therefore, underfill is the main and most damaging defect in laser-welded Ti-6Al-4V. Based on the evaluation of the local tensile behavior, a threshold underfill depth (6 pct of the work piece thickness) is recommended for laser-welded Ti-6Al$4 \mathrm{~V},{ }^{[10]}$ which is slightly more stringent than the AWS D17-1 ${ }^{[27]}$ standard where the maximum underfill depth allowable in the weld is 7 pct of the sheet thickness. In this study, the maximum underfill depths of approximately 4.1 pct and 5.5 pct of the sheet thickness were obtained for the 3.2-mm- and 5.1-mm-thick welds, respectively. The strain concentration was localized in the HAZ, but the welds failed in the BM in the as-welded and SRA conditions. This is in agreement with the recommended threshold of the underfill depth. However, the welds failed in the HAZ or FZ in the STA condition, indicating that a lower 


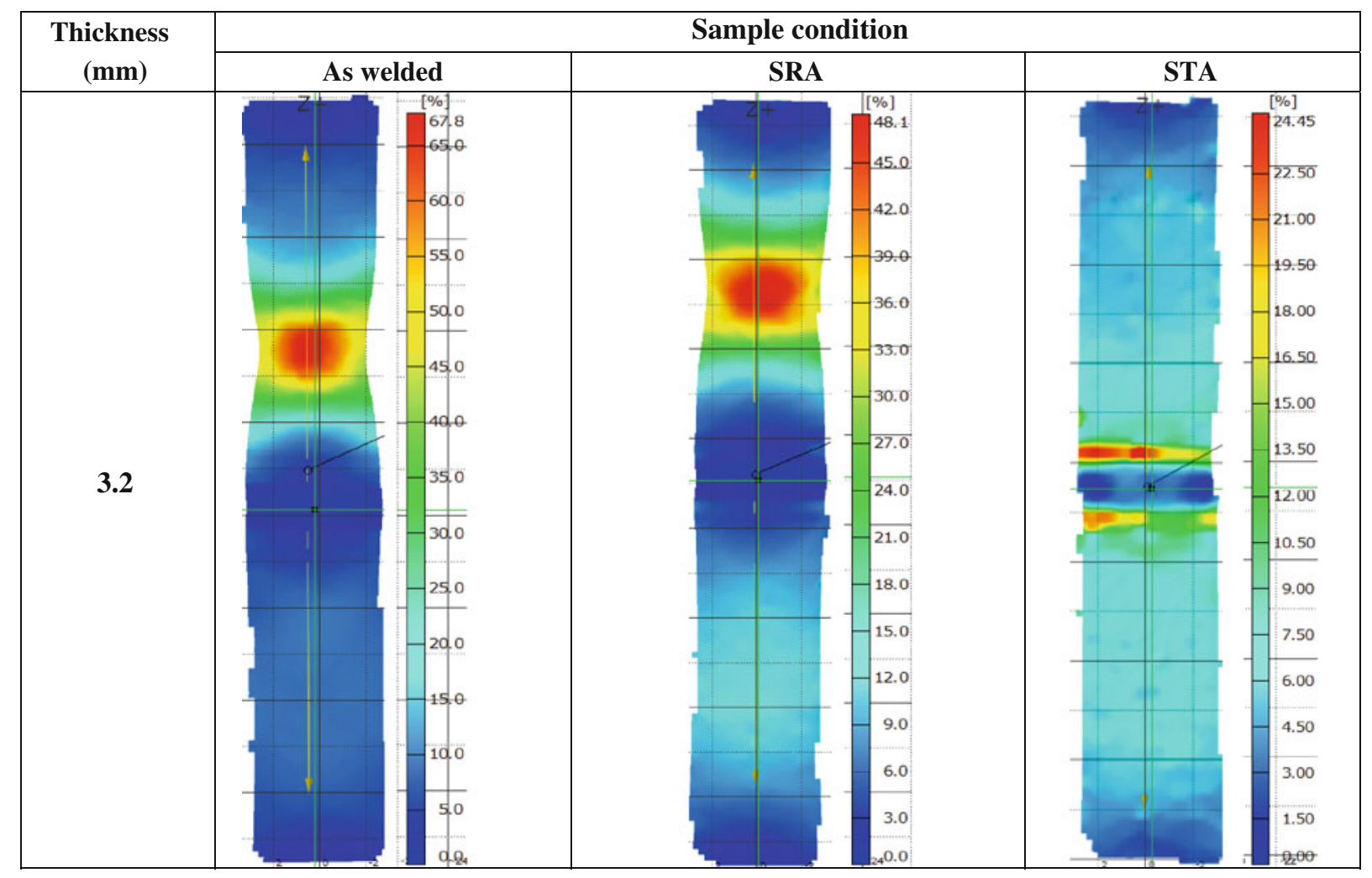

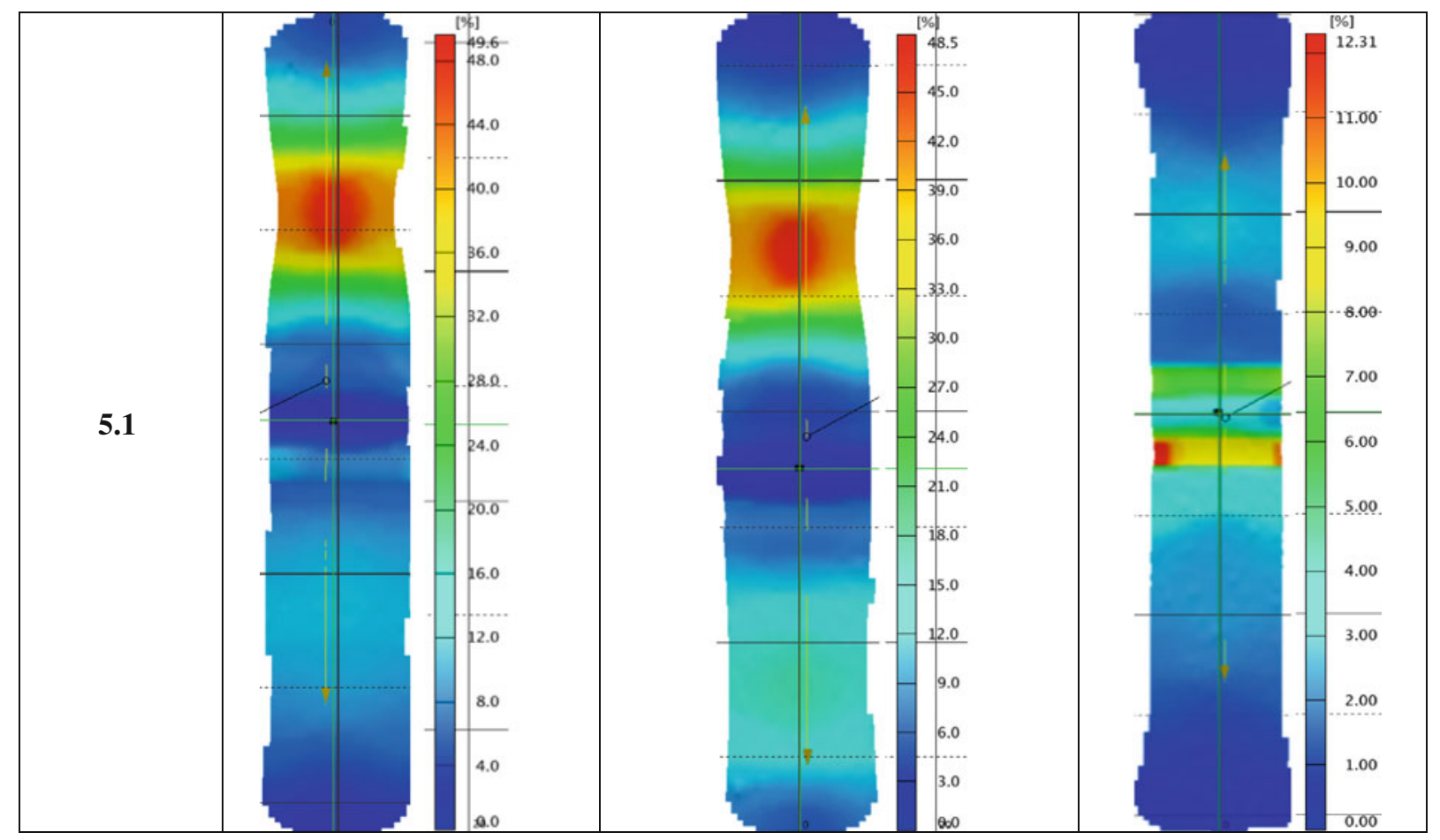

Fig. 13-Major strain maps just before the tensile failure in the as-welded, SRA, and STA conditions for the two sheet thicknesses.

underfill depth is required for the Ti-6Al-4V laser welds if used in the STA condition because of the weakened microstructure.

For each condition, the yield stress is minimum in the HAZ (Figures 14(c) and (d)) and increases toward the FZ, where the value is higher than that of the BM in the as-welded and SRA conditions or reaches close to that of the BM in the STA condition. The local yield strength values are similar in the as-welded and SRA conditions because of their similar structure. The yield stress values of the FZ, HAZ, and BM in the STA condition were less than those of the as-welded or SRA 
$3.2 \mathrm{~mm}$

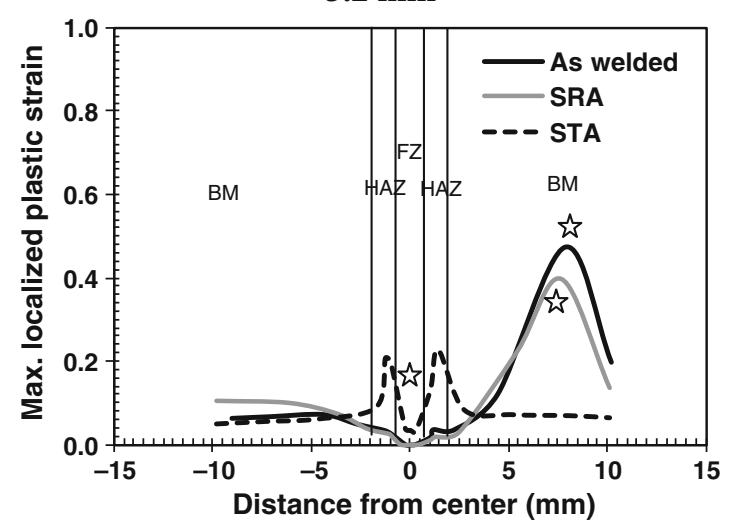

(a)

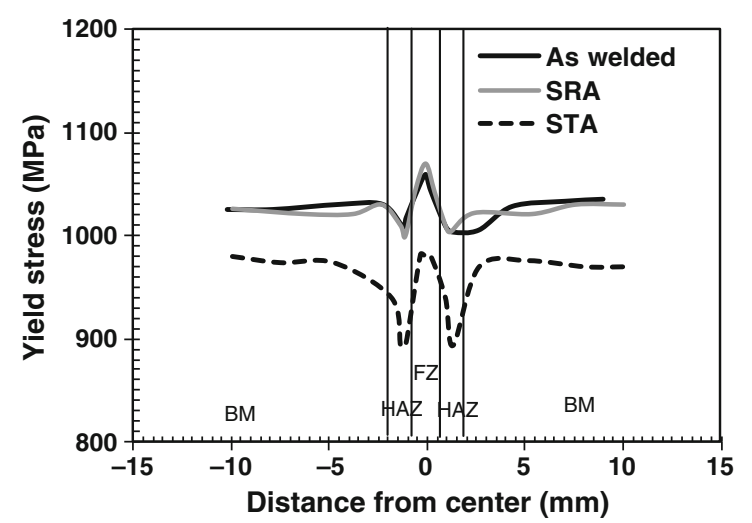

(c)

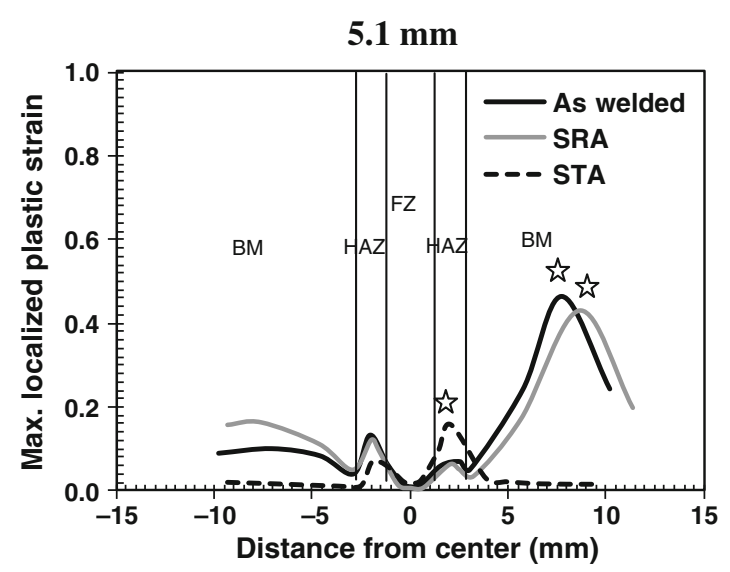

(b)

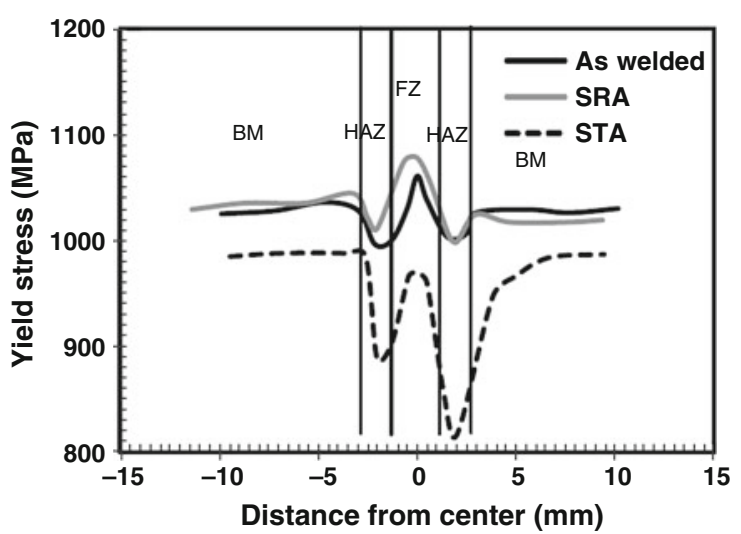

(d)

Fig. 14 -Distributions of the local tensile properties for as-welded, SRA, and STA conditions. The failure location of the sample is indicated by a star.

conditions. These may be associated with the change in the BM, FZ, and HAZ microstructures after STA, as described previously. These findings are expected because of the relative sensitivity of the mechanical properties to the processing conditions for $\mathrm{Ti}-6 \mathrm{Al}-4 \mathrm{~V}$; that is, the changes in thermomechanical history (e.g., cooling rate, heat treatment temperature, and deformation), and thus inevitably the microstructure, have been reported to affect the yield stress of Ti-6Al-4V markedly. ${ }^{[42-45]}$ It is noteworthy that the yield stress determined for the BM by DIC is almost similar to that reported by Cao et al. ${ }^{[13]}$ taken from the same batch material, which validates the DIC evaluations in this work.

\section{CONCLUSIONS}

Two PWHT conditions, i.e., SRA and STA, were performed after laser welding for 3.2-mm- and 5.1-mmthick Ti-6Al-4V. The effect of the PWHT was compared with the as-welded condition in terms of the weld geometry, microstructure, defects, hardness, and tensile properties (global and local). The following conclusions can be drawn:

1. Although no cracking was observed, the welds were noted to have underfill defects and porosity. The maximum underfill depth was well within the AWS specification, but underfill was the main defect because of its strain concentration effect.

2. The fusion zone structure was transformed to a platelet $\alpha$ with interlamellar $\beta$ in the STA condition compared with the martensite or a combined structure of both martensitic and Widmanstätten $\alpha$ in the as-welded and SRA conditions.

3. Compared with the as-welded condition, SRA further increased the hardness in the fusion zone and the HAZ, whereas the STA condition decreased the hardness values in the fusion zone and HAZ. In all conditions, the fusion zone has a maximum hardness, whereas the hardness in the HAZ lies between the fusion zone and the base metal.

4. The joint efficiency in terms of tensile strength is the maximum for the as-welded condition and minimum for the STA condition, but a joint strength of nearly 100 pct was obtained for the as-welded, SRA, and STA conditions. The yield strength is also similar to that of the base metal but the laser welds show significant losses in ductility, particularly after STA.

5. Localized maximum plastic strain at fracture in the fusion zone or HAZ is much lower than that of the base metal. 
6. Compared with the base metal, the local yield stress increases in the fusion zone but decreases in the HAZ in the as-welded condition. Similar local yield strength and distribution are obtained in the SRA and as-welded conditions. However, the local yield strength decreases for all regions after STA.

\section{ACKNOWLEDGMENTS}

The authors are thankful to E. Poirier, X. Pelletier, and D. Chiriac for their technical support during the laser welding, sample preparation, and tensile testing with ARAMIS.

\section{REFERENCES}

1. G. Lutjering and J.C. Williams: Titanium, 2nd ed., Springer, Berlin, Germany, 2007.

2. C. Leyens and M. Peters, eds.: Titanium and Titanium Alloys. Fundamentals and Applications, Wiley-VCH Verlag GmbH \& Co., Weinheim, Germany, 2003.

3. A.B. Short:, Mater. Sci. Tech., 2009, vol. 25, pp. 309-24

4. Q. Yunlian, D. Ju, H. Quan, and Z. Liying: Mater. Sci. Eng., A, 2000, vol. 280, pp. 177-81.

5. E. Akman, A. Demir, T. Canel, and T. Sinmazçelik: J. Mater. Process. Tech., 2009, vol. 209, pp. 3705-13.

6. F. Caiazzo, F. Curcio, G. Daurelio, and F.M.C. Minutolo: J. Mater. Process. Tech., 2004, vol. 149, pp. 546-52.

7. L. Tsay, Y.P. Shan, Y.H. Chao, and W. Shu: J. Mater. Sci., 2006, vol. 41, pp. 7498-7505.

8. ASM Handbook: Welding, Brazing, and Soldering, ASM International, Materials Park, OH, 1993.

9. X. Cao and M. Jahazi: Opt. Laser Eng., 2009, vol. 47, pp. 1231-41.

10. A.S.H. Kabir, X. Cao, J.G. Baradari, P. Wanjara, J. Cuddy, A. Birur, and M. Medraj: Adv. Mater. Res., 2012, vol. 409, pp. 85964.

11. A.S.H. Kabir, X. Cao, P. Wanjara, J.G. Baradari, J. Cuddy, A. Birur, and M. Medraj: Conf. Proc. Materials Science and Technology, MS\&T, Houston, TX, 2010, pp. 2787-97.

12. X. Cao, G. Debaecker, M. Jahazi, S. Marya, and A. Birur: Mater. Sci. Forum, 2010, vol. 638, pp. 3655-60.

13. X. Cao, G. Debaecker, E. Poirier, S. Marya, J. Cuddy, A. Birur, and P. Wanjara: J. Laser Appl., 2011, vol. 23, pp. 1-10.

14. ASTM E384-05, Standard Test Method for Microhardness of Materials, 1999.

15. ASTM E 8M-04, Standard Test Methods for Tension Testing of Metallic Materials, 2004.

16. W.H. Peters and W.F. Ranson: Opt. Eng., 1982, vol. 21, pp. $427-31$.
17. M.A. Sutton, W.J. Wolters, W.H. Peters, W.F. Ranson, and S.R. McNeill: Image Vis. Comput., 1983, vol. 1, pp. 133-39.

18. T. Chu, W. Ranson, and M. Sutton: Exp. Mech., 1985, vol. 25, pp. 232-44.

19. H. Bruck, S. McNeill, M. Sutton, and W. Peters: Exp. Mech., 1989, vol. 29, pp. 261-67.

20. P. Rastogi, M. Sutton, S. McNeill, J. Helm, and Y. Chao: Top. Appl. Phys., 2000, vol. 77, pp. 323-72.

21. W.D. Lockwood and A.P. Reynolds: Mater. Sci. Eng. A, 2003, vol. 339 , pp. 35-42.

22. W.D. Lockwood, B. Tomaz, and A.P. Reynolds: Mater. Sci. Eng. A, 2002, vol. 323, pp. 348-53.

23. M. Pastor, H. Zhao, R.P. Martukanitz, and T. DebRoy: Weld. J., 1999, vol. 78 , pp. $207 \mathrm{~s}-16 \mathrm{~s}$.

24. T. Shariff, X. Cao, R. Chromik, J. Gholipour, P. Wanjara, J. Cuddy, and A. Birur: Can. Metall. Q., 2011, vol. 50, pp. 263-72.

25. S.H. Wang, M.D. Wei, and L.W. Tsay: Mater. Lett., 2003, vol. 57, pp. $1815-23$.

26. J.C. Ion: Laser Processing of Engineering Materials; Principles, Procedure and Industrial Application, Elsevier ButterworthHeinemann, Oxford, U.K., 2005.

27. AWS D17.1, Specification for Fusion Welding for Aerospace Application, 2001.

28. X. Cao, M. Jahazi, J.P. Immarigeon, and W. Wallace: J. Mater. Process. Tech., 2006, vol. 171, pp. 188-204.

29. Z. Khaled: J. Mater. Eng. Perform., 1994, vol. 3, pp. 419-34.

30. Q. Han: Scripta Mater., 2006, vol. 55, pp. 871-74.

31. A.H. Kazzaz, M. Medraj, X. Cao, M. Jahazi, and M. Xiao: Conf. Proceedings, $44^{\text {th }}$ Annual Conference of Metallurgist of CIM, Calgary, AL, 2005, pp. 137-49.

32. W.W. Duley: Laser Welding, Wiley-Interscience, NJ, 1998.

33. A. Matsunawa, J.-D. Kim, N. Seto, M. Mizutani, and S. Katayama: J. Laser Appl., 1998, vol. 10, pp. 247-54.

34. M. Pastor, H. Zhao, and T. DebRoy: Rev. Metal. Madrid, 2000, vol. 36, pp. $108-17$.

35. X. Cao, W. Wallace, C. Poon, and J.P. Immarigeon: Mater. Manuf. Process., 2003, vol. 18, pp. 23-49.

36. T. Ahmed and H.J. Rack: Mater. Sci. Eng. A, 1998, vol. 243, pp. 206-11

37. P. Wanjara, M. Brochu, and M. Jahazi: Mater. Manuf. Process., 2006, vol. 21, pp. 439-51

38. P. Azar, P. Li, P.C. Patnaik, R. Thamburaj, and J.-P. Immarigeon: RTO-MP, 2001, vol. 69, pp. 18.1-18.16.

39. L.W. Tsay and C.Y. Tsay: Int. J. Fatigue, 1997, vol. 19, pp. 71320.

40. W.A. Baeslack and C.M. Banas: Weld. J., 1981, vol. 60, pp. 121S$30 \mathrm{~S}$.

41. G. Thomas, V. Ramachandra, M.J. Nair, K.V. Nagarajan, and R. Vasudevan: Weld. J., 1992, vol. 71, pp. 15s-20s.

42. Y. Lee, M. Peters, and G. Welsch: Metall. Trans. A, 1991, vol. 22A, pp. 709-14.

43. Y.T. Lee and G. Welsch: Mater. Sci. Eng. A, 1990, vol. 128, pp. $77-89$.

44. Z. Fan: Scripta Metall. Mater., 1993, vol. 29, pp. 1427-32.

45. R. Boyer, G. Welsch, and E.W. Collings: Materials Properties Handbook: Titanium Alloys, ASM International, Materials Park, OH, 1994, pp. 493-95. 